are necessary to predict the torque on a permanent magnet, should not the question of forces on a current-carrying conductor immersed in a magnetic medium be re-examined? Consider as an example a thin film-shaped conductor immersed in a medium of relative permeability $\mu_{r}$. The permeability of the conductor is identical with that of a vacuum just as Smythe assumed for a magnet and both $\mathbf{B}$ and $\mathbf{H}$ are parallel to the plane of the film. It is certain that $\mathbf{H}$ in the film is precisely the same as $\mathbf{H}$ in the medium and, also, for an experiment similar to that of Whitworth and Stopes-Roe, neglecting the self-demagnetizing field of the tank, it is the same as if the paramagnetic liquid were removed. $\mathbf{B}$ in the conductor is also the same as if the liquid were removed. If the electric current is due to electrons moving in a medium with the same permeability as free space, it is difficult to avoid the conclusion that the force on these electrons is not affected by surrounding the conductor with a magnetic medium.

If, however, the plane of the conductor is turned so that it is normal to the field, both $\mathbf{B}$ and $\mathbf{H}$ within the conductor are increased. To assume, however, that the force depends on the orientation of the conductor leads to difficulties-two currentcarrying conductors should experience equal and opposite forces. There seem to be two possible solutions to this paradox. One is to suppose that the force on a conductor whatever its orientation is unaffected by a surrounding medium. This could be justified by saying that any change in $\mathbf{B}$ or $\mathbf{H}$ when the medium is introduced arises from unanchored fluid molecules incapable of exerting a force on the conductor. An alternative suggestion was made during a discussion on this subject at the June 1972 meeting of the Magnetism Group of the Institute of Physics in Oxford. According to this suggestion part of the force on the conductor may arise from a hydrostatic pressure gradient in the fluid. Such a force might vindicate the generally accepted assumption that the force on a current-carrying conductor is proportional to $\mathbf{B}$.

Whitworth and Stopes-Roe have shown that these questions can be investigated experimentally, and more experiments are clearly desirable. In general in such experiments, the selfdemagnetizing field of the tank may need to be considered, although Whitworth and Stopes-Roe seem to have eliminated this factor with their particular arrangement.

I thank Dr F. J. Lowes for comments and for drawing my attention to ref. 2 .

Permanent Magnet Association,

M. MCCRAIG

Central Research Laboratory,

84 Brown Street,

Sheffield $S 11 F A$

Received December 7, 1972.

1 Whitworth, R. W., and Stopes-Roe, H. V., Nature, 234, 31 (1971).

2 Smythe, W. R., Static and Dynamic Electricity, 357 (McGraw-Hill, New York, 1960).

\section{Preparation of Tritium-labelled Talc}

TALC, a native hydrous magnesium silicate approximating to the general formula $\mathrm{Mg}_{3} \mathrm{Si}_{4} \mathrm{O}_{10}(\mathrm{OH})_{2}$, is extensively used in industry in addition to its wide acceptance as a cosmetic and toiletries product. Although chemically inert, it produces a number of biological effects including tissue granulomata ${ }^{1,2}$ and a form of pneumoconiosis after inhalation ${ }^{3,4}$. A recent report $^{5}$ suggesting an association of cancer of the cervix and ovaries with the presence of talc particles at these sites has caused disquiet about its safety in use. Although the evidence is equivocal, it follows the acceptance of a causal relationship between exposure to asbestos dust and mesothelioma ${ }^{6}$.

The detection of talc particles in tissues, essential for the elucidation of the mechanisms of pathogenicity, presents considerable difficulties. Although the extraction replication technique developed by Henderson et al. ${ }^{7}$ offers an elegant means for the identification of talc particles in tissues, the small areas that can be surveyed by electron microscopy do not provide an overall picture of particle distribution. Furthermore, the adventitious contamination of tissues during the preparation of specimens for examination cannot be ruled out. The value of using a suitably labelled radioactive talc for such studies is self-evident, and the use of tritium-labelled asbestos ${ }^{8}$ has greatly facilitated the localization of asbestos fibres in tissues.

A method has now been developed for the preparation of tritium-labelled talc. The process involves two stages; first, the partial dehydration of talc under controlled conditions, and second, the rehydration of the material using tritiated water. The talc used conformed with the specifications of the British Pharmacopoeia 1968.

The partial dehydration of talc was effected by heating talc in a platinum dish at $835-840^{\circ} \mathrm{C}$ for $1 \mathrm{~h}$ resulting in the loss of 1 molecule of $\mathrm{H}_{2} \mathrm{O}$. The study of the dehydration of kinetics of talc showed that below this temperature no loss of $\mathrm{H}_{2} \mathrm{O}$ occurred, and that at temperatures in excess of $900^{\circ} \mathrm{C}$ the second molecule of $\mathrm{H}_{2} \mathrm{O}$ was lost, gradually leading eventually to complete dehydration at $1,000^{\circ} \mathrm{C}$. The reincorporation of 1 molecule of $\mathrm{H}_{2} \mathrm{O}$ into the partially dehydrated talc was achieved by refluxing the material with 50 volumes of benzene/ water azeotropic mixture $(92: 8)$ for $2 \mathrm{~h}$. The talc was filtered on a No. 4 sintered glass filter crucible and the last traces of solvents removed at $130^{\circ} \mathrm{C}$ under vacuum. Electron microscopy and X-ray diffraction studies showed that the rehydrated material was virtually identical with and indistinguishable from the original talc. It was found that talc could be repeatedly subjected to the processes of partial dehydration and rehydration, employing the methods described, without any substantial alteration in its physical properties or chemical composition.

The efficiency of the rehydration procedure was considerably improved by heating the partially dehydrated talc and 5 volumes of benzene/water azeotropic mixture contained in sealed ampoules in an autoclave at 15 pound inch ${ }^{-2}$ pressure for $30 \mathrm{~min}$. The ampoules were opened, centrifuged at 3,000 r.p.m. for $5 \mathrm{~min}$ and the supernatant liquid decanted. The rehydrated talc was washed twice with distilled water, recentrifuged and finally dried at $130^{\circ} \mathrm{C}$ under vacuum. This procedure was adopted for the incorporation of tritiated water into talc, and the inclusion of tritiated water into the benzene/water mixture $\left(0.5 \mathrm{mCi} \mathrm{ml} .^{-1}\right)$ resulted in the formation of tritium-labelled talc $(15,000$ d.p.m. $\mathrm{mg}^{-1}$ ). The thermal stability of this labelled material was similar to that of the rehydrated talc and there was no evidence of exchange with $\mathrm{H}_{2} \mathrm{O}$ at $100^{\circ} \mathrm{C}$.

Biological investigations on the tissue distribution of the tritium-labelled talc are currently in progress.

We thank Mr J. K. Foreman for X-ray diffraction studies.

S. D. GANGOLLI

R. F. CRAMPTON

A. G. Lloyd

The British Industrial Biological Research Association,

Woodmansterne Road,

Carshalton, Surrey

Received January 17, 1973.

${ }^{1}$ Tye, M. J., Hashimoto, K., and Fox, F., J. Amer. Med. Ass., 198, 1370 (1966).

2 Migaki, G., and Garner, F. M., Amer. Vet. Med. Ass., 155, 1595 (1969).

${ }^{3}$ Van Ordstrand, H. S., Chest, 58, 2 (1970).

${ }^{4}$ Miller, A., Teirstein, A. S., Bader, M. E., Bader, R. A., and Selikoff, I. J., Amer. J. Med., 50, 395 (1971).

${ }^{5}$ Henderson, W. J., Joslin, C. A. F., Turnbull, A. C., and Griffiths, K., J. Obs. Gyn. Br. Comm., 78, 266 (1971).

${ }^{6}$ Selikoff, I. J., Bader, R. A., Bader, M. E., Churg, J., and Hammond, E. G., Amer. J. Med., 42, 487 (1967).

${ }^{7}$ Henderson, W. J., Harse, J., and Griffiths, K., Europ. J. Cancer, $5,621(1969)$

${ }^{8}$ Turncock, A. C., Bryks, S., and Bertalanffy, F. D., Environ. Res., 4, 86 (1971) 